\title{
PROCESSOS CRIATIVOS NA PRODUÇÃO ACADÊMICA EM TEMPOS DE PANDEMIA
}

\section{Resumo}

Esse trabalho propõe uma reflexãodas narrativas de três pesquisadoresque relatam sobre os seus processos criativos no período do distanciamento social causado pela Covid-19. O objetivo foi perceber os processos de subjetividade que podem impactarna elaboração da pesquisa acadêmica no período da pandemia. De modo a identificar as práticas, as experiências e a construção do sujeito - pesquisador. Metodologicamente, é um estudo de abordagem qualitativa a partir da relação entre as entrevistas narrativas do método (auto)biográfico e o referencial teórico. Evidenciamos por meio desse estudo que a construção de uma subjetividade perpassa pela influência do meio social em um tempo de lutas e de incertezas no contexto político. Nos processos de investigação acadêmica, o sujeito-pesquisador é atravessado por uma subjetividade nas suas produções e se vê desafiado a utilizar de sua criatividade para o fazer científico. Os elementos que orientam as reflexões aqui desenvolvidas destacam-se: o reconhecimento de técnicas de resistência do sujeito, o ato de narrar como ponto de encontro da sua transformação e a produção de si e dos processos criativos.

Palavras - Chave: Processos Criativos. Pandemia. EntrevistasNarrativas. Sujeito. Subjetividade

\section{CREATIVE PROCESSES IN ACADEMIC PRODUCTION IN PANDEMIC TIMES}

\begin{abstract}
This work proposes a reflection on the narratives of three researchers who report on their creative processes in the period of social distance caused by Covid-19. The objective was to understand the processes of subjectivity that can impact the development of academic research during the pandemic period. In order to identify the practices, experiences and construction of the subject - researcher. Methodologically, it is a study with a qualitative approach based on the relationship between the narrative interviews of the (auto) biographical method and the theoretical framework. Through this study, we have evidenced that the construction of subjectivity goes through the influence of the social environment in a time of struggles and uncertainties in the political context. In academic research processes, the subject-researcher is subject to a subjectivity in his productions and is challenged to use his creativity to do scientific work. The elements that guide the reflections developed here stand out: the recognition of the subject's resistance techniques, the act of narrating as a meeting point for his transformation and the production of himself and the creative processes.
\end{abstract}

Keywords: Creative Processes. Pandemic. Narrative Interviews. Subject. Subjectivity 


\section{PROCESOS CREATIVOS EN LA PRODUCCIÓN ACADÉMICA EN TIEMPOS DE PANDEMIA}

\section{Resumen}

Este trabajopropone una reflexión sobre las narrativas de tres investigadores que informan sobre sus procesoscreativosenel período de distanciamiento social provocado por Covid-19. El objetivo fuecomprenderlosprocesos de subjetividad que pueden impactar eldesarrollo de lainvestigación académica durante el período pandémico. Conelfin de identificar lasprácticas, vivencias y construccióndelsujeto - investigador. Metodológicamente, es unestudiocon enfoque cualitativobasadoenlarelación entre las entrevistas narrativas del método (auto) biográfico y el marco teórico. A través de este estudio, hemos evidenciado que laconstrucción de lasubjetividadpasa por la influencia del entorno social en una época de luchas e incertidumbresenel contexto político. Enlosprocesos de investigación académica, elsujeto-investigador está sujeto a una subjetividaden sus producciones y se ledesafía a utilizar sucreatividad para realizar untrabajo científico. Destacanlos elementos que orientanlas reflexiones aquídesarrolladas: elreconocimiento de las técnicas de resistenciadelsujeto, elacto de narrar como punto de encuentro para sutransformación y laproducción de símismo y losprocesoscreativos.

Palabras - clave: Procesoscreativos. Pandemia. Entrevistas narrativas. Tema. Subjetividad

\section{Notas Introdutórias}

Ando muito completo de vazios. Meu órgão de morrer me predomina. Estou sem eternidades. Não posso mais saber quando amanheço ontem.

Está rengo de mim o amanhecer. Ouço o tamanho oblíquo de uma folha.

Atrás do ocaso fervem os insetos. Enfiei o que pude dentro de um grilo o meu destino.

Essas coisas me mudam para cisco. A minha independência tem algemas.

(Manoel de Barros, 1996) ${ }^{1}$

A letra do poema de Manoel de Barros que usamos como epígrafe, têm a importância de revelar para nós, os sentimentos que o poder das palavras nos traz na

\footnotetext{
${ }^{1}$ Trecho do poema "Os deslimites da palavra"escrito por Manoel de Barros em o "Livro sobre nada", 1996. Disponível em: https://recantodopoeta.com/os-deslimites-da-palavra/, acesso em 28 ago 2020.
} 
contemporaneidade. Nos provoca a pensar em uma ciência mais sensível acionando nossos processos de subjetivação do mundo. É lembrar que “[...] o sujeito é ativo, atuante na sociedade em que está inserido, um sujeito que age no mundo através do discurso, constituindo a realidade e a si mesmo no processo de interação dos indivíduos em um determinado espaço social” (MOREIRA E SILVEIRA, 2011, p.63).

Debater sobre as ressignificações que o ano de 2020 trouxe para cada um de nós e para toda a humanidade é trazer consigo a esperança de um amanhecer melhor. Isso porque a ação de um vírus o qual não o vemos e nem o tocamos tem nos despertadoum sentimento que muitas vezes é inexpressivo do ponto de vista da subjetividade de cada um de nós.

E assim, toda a sociedade foi atingida, as ruas ficaram mais vazias, todos em um recolhimento para si ou para as telas. Tivemos que fechar as portas das escolas e universidades. Foi preciso que os professores e estudantes se adaptassem à nova maneira de viver e se relacionar socialmente.Surge então a necessidade de se reinventar, mudar, produzir novas formas discursivas e de provocar modos de subjetivação dos sujeitos.

Dentro desse contexto, é importante considerar que os processos criativosformativos são de autoaprendizagem, pois perpassam a forma de lidar com a vida. Sobre essa questão, Nóvoa e Finger (2010, p. 116) afirmam que:

As histórias de vida e o método (auto)biográfico integram-se no movimento actual que procura repensar as questões da formação, acentuando a ideia que 'ninguém forma ninguém' e que 'a formação é inevitavelmente um trabalho de reflexão sobre os percursos de vida'.

Nessa perspectiva, o método (auto)biográfico vai proporcionar aos narratáriose aos narradores (re)pensar sobre o seu percurso de vida. Promovendo e evocando o (re)conhecimento dos itinerários formativos dos sujeitos-pesquisadoresem tempos de pandemia. Essas narrativas contribuem também, para que possamos pensar as subjetividades contidas no seu fazer pedagógico e estabelecer relações com contextos e problemáticas mais amplas.

Além disso, nos propomos dentro do processo de análise das narrativas, ressignificar e reinterpretar os olhares que temos de nós mesmos e de nossa identidade enquanto pesquisadores, pondo em evidência emoções e razões as quais antes não tínhamos percebido. De acordo com Schütze (1992b, p.8 -9), por meio da: 
[...] narração [...] de certas fases e episódios da vida [...], o narrador exprime uma ordem e estrutura de identidade básica para a sua vida que é vivida e experenciada até o momento e que se expande em direção ao futuro que está por vir. A expressão narrativa da própria vida lida não apenas com eventos externos que ocorrem com o indivíduo, mas também com as mudanças internas que a pessoa deve enfrentar ao experenciar, reagir emoldar (e até parcialmente produzir) esses eventos externos. E reconhecendo, através da narração [...] como alguém se sentiu ao experenciar os eventos externos é um primeiro passo para o indivíduo equacionar a contínua construção e transformação de seus estados internos e sua importância, para a estrutura da identidade da história de vida em desenvolvimento.

Assim, nas diferentes escalas da interpretação narrativa, as vidas vão se (re)construindo em espirais cada vez mais complexos, fechando tempos e abrindo novas perspectivas. Talvez esta prerrogativa nos permita olhar com uma melhor compreensão do significado do tempo em que estamos vivendo e as atividades que estamos realizando.

\section{Sujeito e suas subjetividades}

[...] Suspender o céu é ampliar o nosso horizonte; não o horizonte prospectivo, mas um existencial. É enriquecer nossas subjetividades, que é a matéria que esse tempo que nós vivemos quer nos consumir. Se existe uma ânsia por consumir a natureza, existe uma ânsia por consumir nossa subjetividade (AILTON KRENAK, 2019, p.32).

Krenaknos aponta que a contemporaneidade tem provocado efeitos no campo da subjetividade.Esses ocorrem por meio dos elementos culturais e socias tais como: o uso intenso dos computadores, a globalização, a comunicação pelas redes digitais e virtuais.Megale e Teixeira (1998) indicam que estamos vivendo transformações nos referenciais tempo e espaço trazendo uma desterritorialização dos corpos e das relações entre sujeitos.

$\mathrm{Na}$ busca de entender esse sujeito, atravessado pelo contexto e pelo jogo de força que o compõe, traremos para essa discussão conceitos importantes como: subjetividade e modos de produção da subjetividade. Se faz necessário entender, que o sujeito não é um 'ente' cristalizado ou dotado de rigidez, a concepção que apresentaremos perpassa pela ruptura desse olhar previsível e já delineado do sujeito. Desse modo, Mansano 
(2009), pautada nos conceitos foucaultianos, pondera que o sujeito se constitui em um campo complexo de muitas forças que o atinge de diferentes maneiras. Esse sujeito se constitui no processo à medida que vai se relacionando e tecendo sua teia de experiências.

A experiência a qual nos ancoramos é tomada em seu sentido pela via mais profunda da palavra. Como bem nos convoca Larrosa (2002, p. 21) "[...] é o que nos passa, o que nos acontece, o que nos toca. Não o que se passa, não o que acontece, ou que toca. A cada dia se passam muitas coisas, porém, ao mesmo tempo, quase nada nos acontece". Comungando com esse modo de pensar,Sitja e Reis (2009) nos trazem a importância de uma experiência que coloca o sujeito sob o constante risco e que fica exposto e não o deixa mobilizado.

$\mathrm{Na}$ medida que o sujeito experiencia e entra em contato com os acontecimentos, as forças que o circundam afetam o seu corpo. Isso vai gerar um movimento que desestabiliza o sujeito. Desse modo, a constituição do sujeito perpassa por uma processualidade, de um vir a ser e não um "ser em si" cristalizado ou definitivo. Essa composição movente do sujeito é permeada de aventuras, sem controle ou planejamento sobre o que irá emergir do contexto. Sendo ela uma composição provisória, pois a qualquer momento o sujeito é tomado de novos movimentos que podem desestabilizar e reorganizar sua composição (MANSANO, 2009).

Nesse interjogo, a partir das relações de poder e de produção política é que o sujeito está posto em uma direção de inacabamento, e assim a subjetividade vai se construindo.Sendo ela "compreendida com um plano de produções histórico-políticas a partir do qual a forma sujeito emerge como efeito" (TEDESCO, 2007, p. 124).

Essa subjetividade, atravessada por um campo de forças, possibilita ao sujeito uma consciência de si, o levando a uma autoconsciência. Sitja e Reis (2009) dizem que "a própria vida passa a ser concebida com um processo de conhecimento contínuo e cíclico", o que nos leva a compreender que a vida é cercada de aprendizagens e descobertas de si e do outro. Esse processo de descoberta de si acontece no ponto mais profundo da experiência e não é um conhecimento de modo objetivo em uma relação tão óbvia ou linear entre o sujeito-objeto, mas em uma relação intensa como nos lembra Amatuzzi (2006).

Aproximando-se desse pensamento,Mansano (2009, p. 111) apoiada nos estudos de Guatarri, nos traz que a subjetividade é "uma produção incessante que acontece a 
partir dos encontros que vivemos com o outro".Esse outro vai para além do outro humano que envolve tudo que circunda o sujeito, inclusive a própria natureza.Desse modo, não sendo possível separar o sujeito do mundo ao qual ele pertence. Tal produção, envolve múltiplos componentes e a cada mudança social interfere diretamente nos processos de produção dessa subjetividade. No cenário da pandemia as atividadesde pesquisa presenciaisse apresentamcom uma nova configuração para os sujeitos-pesquisadores. Entendendo que a presença coletiva proporciona condições de socialização, sendo fundamentalpara os processos criativos e de formação dos sujeitos.

Buscando compreender os componentes subjetivos que se organizam, a partir dessa conjuntura, vemos que esses se agrupam e recebem contornos distintos, propondo uma passagem pelos modos de subjetivação. Com olhar voltado para os estudos de Foucault, Mansano(2009) nos convoca a uma reflexão sobre a dimensão histórica que atravessa os modos de subjetivação, descartando a possibilidade de uma universalização, e defendendo a singularidade do sujeito.

Esse sujeito, em deslocamento, ao lançar-se em suas experiências passa a descobrir quem é, nesse entrelaçamento é influenciado pelo outro e pelo meio social. A despeito disso os "modos de subjetivação podem tomar as mais diferentes configurações, sendo que estas cooperam para produzir formas de vida e formas de organização social distintas [...]"(MANSANO, 2009, p. 114).Dentro do modo de produção da subjetividade, a linguagem é um dos componentesconstituinte do sujeito que é atravessada pelos interdiscursos.Como diz Tedesco (2007, p.145) "o encadeamento de discursos produz as condições discursivas, ou seja, impõe o enquadre da conversação, determinando o que pode ser tido. A linguagem institui novas realidades a serem tratadas, novos objetos empíricos".

\section{Dialogando sobre o método}

Você sabe só existe o que é dito. Nem você, nem eu, nem ninguém existe sem a narrativa de nossa existência, mesmo uma coisa, é preciso narrá-la para que ela ocorra (Michel Serres).

Iniciamos essa sessãoque se propõe a dialogar sobre o método utilizado,no referido trabalho, com uma reflexão de Michel Serres, na qual o autor elucida a 
importância da narrativa para a nossa existência, partindo do entendimento de que o ato de narrar consiste em uma produção de sentidos estabelecida, através da iniciativa do sujeito em refletir sobre sua trajetória e o desejo denarrá-la, seja ela de maneira oral ou escrita. No âmbito dessa discussão, Ricoeur (2006. p. 115) ressalta a importância de "[...] narrar-se, aprender a narrar-se é também aprender a narrar a si mesmo de outro modo". E com isso a quem narra, cabe escolher o que será revelado e por conta disso, a (auto)biografia se atém a seleção de fatos, efetivados pelo narrador.

Diante disso, no que se refere ao aspecto metodológico, a análise em questãoéfundamentada na perspectiva deuma abordagem qualitativa,que segundo Minayo (2010, p. 57) “[...]se aplica ao estudo da história, das relações, das representações, das crenças, das percepções e das opiniões, produtos das interpretações que os humanos fazem a respeito de como vivem, constroem seus artefatos e a si mesmos, sentem e pensam".

Dessa forma,nos ancoramos à pesquisa (auto)biográfica, através da utilizaçãoda entrevista narrativaque é um dispositivo de coleta de dados de pesquisa sociológica, cujo objetivo é reconstruir acontecimentos sociais a partir da perspectiva de quem narra(SCHÜTZE, 1992a).Trazendo como colaboradoresos sujeitos-pesquisadores, possibilitandoque sejam evidenciados por meio das narrativas as suas compreensões acerca das experiências sobre os processos criativos em tempos de pandemia.Entendendo que "[...]a experiência é pessoal e social. Tanto o pessoal, quanto o social estão sempre presentes" (CLANDININ y CONNELY, 2015, p. 30).

Visando ainda contribuir para o entendimento, sobre o método escolhido nesse artigo podemos ressaltar que:

\begin{abstract}
As entrevistas narrativas se caracterizam como ferramentas não estruturadas, visando a profundidade, de aspectos específicos, a partir das quais emergem histórias de vida, tanto do entrevistado como as entrecruzadas no contexto situacional. Esse tipo de entrevista visa encorajar e estimular o sujeito entrevistado (informante) a contar algo sobre algum acontecimento importante de sua vida e do contexto social(JOVCHELOVICH y BAUER,2002, p. 90).
\end{abstract}

Nesse cenário, é relevante salientar algumas considerações sobre o método (auto)biográfico, que segundo Mota (2016) é um processo autoformativo quepermite ao sujeito um protagonismo em seu pensar sobre sua prática e sua formação. Com isso, o método (auto)biográfico permite que seja: processos das pessoas que se formam: nisso reside uma das suas principais 
qualidades, que o distinguem, aliás, da maior parte das metodologias de investigação em ciência sociais (NÓVOA; FINGER, 2010, p. 23).

Na proposta de uma contextualização, Nóvoa e Finger (2010) ressaltam que a utilização do método (auto)biográfico nas ciências da educação é relativamente recente. Essa perspectiva metodológica surgiu inicialmente na Alemanha no final do século XIX, como uma alternativa sociológica ao positivismo. Aplicada pela primeira vez de forma sistemática em 1920 por sociólogos americanos da Escola de Chicago, logo despertou polêmicas em torno de sua epistemologia. Desde então, seu uso de forma autônoma tem sido reivindicado por estudiosos do método.

Perez (2003, p. 03) afirma que a “[...] a narrativa autobiográfica é um texto vivo, de um sujeito historicamente datado e socialmente situado; um texto revela modos de pensamento e reflete formas de organizar e criar e recriar cotidianamente o mundo". A autora ainda evidencia que existem dois caminhos para a utilização da narrativa autobiográfica: a investigação da narrativa usada no ensino e a pesquisa que faz uso da narrativa. Deste modo, as narrativas podem ser tanto um fenômeno que se investiga, quanto um método de investigação. Diante dessa reflexão, podemos salientar que:

\footnotetext{
As narrativas propõem uma nova Epstein, um novo tipo de conhecimento, que emerge não na busca de uma verdade, mas de uma reflexão sobre a experiência narrada, assegurando um novo posicionamento político em ciência, que implicam princípios e métodos legitimadores da palavra do sujeito social, valorizadores de sua capacidade de reflexão, em todas as idades, independentemente do gênero, etnia, cor, profissão, posição social, entre outras opções (PASSEGI y SOUZA, 2016, p. 06).
}

Quanto ao formato de análise das entrevistas narrativas é importante destacarque a mais adequada para esse objeto de estudo é a compreensiva - interpretativa, pois, concebe entre si relações de dialogicidade e reciprocidade.Tendo em vista aproximações e vizinhanças,mas também singularidades em seus tempos e momentos de análise.Essa é compreendida em três tempos: Tempo I: Pré-análise / leitura cruzada; - Tempo II: Leitura temática - unidades de análise descritivas; - Tempo III: Leitura interpretativacompreensiva do corpus(SOUZA, 2006a).

\section{Interlocução com as narrativas}

Pensar a palavra e a narrativa como um ato de subjetivação circunscreve-se num panorama de evocação do diálogo e da argumentação sobre um determinado fenômeno. Visto que, a narrativa expressa tanto os pensamentos e sentimentos 
singulares, como os significados sociais embutidos nos sistemas culturais e em seu caráter conotativo.Influenciando assim, no processo de interação homem, ambiente e de sua própria constituição como sujeito (OLIVEIRA, SATRIANO, 2014).

A constituição de si e as variações produzidas pelos encontros intensivos são, portanto, um encontro com o outro que nos remete a um campo complexo de problematizações, por conta do caráter provisório dos acontecimentos e suas reverberações (MANSANO, 2009). Nesse sentido "a experiência narrada resgata um momento vivido e se transforma em uma nova experiência para quem narra e para quem ouve. No momento em que é transmitida a outras pessoas, ela ganha vida e significado" (SOUZA,2020, p.84).

Desse modo, nessa sessão faremos um diálogo entre o referencial teórico e as narrativas dos sujeitos-pesquisadores acerca dos "processos criativos" "em tempos de pandemia". Com o intuito de preservar a identidade dos narradores-participantes utilizaremos o sistema alfanuméricoSP1, SP2 e SP3 para nomeá-los.

Iniciamos essa interlocução destacando os desafios encontrados pelos sujeitos nesse contexto nas dimensões subjetivas, profissionais e sociais. Para elucidar, essa afirmativa o Sujeito- Pesquisador 1 (SP1) ressalta que:

[...] Existem muitos desafios que eu encontrei nesse percurso e estou encontrando. Sou mãe de duas moças, casada, coordenadora pedagógica e mestranda. Então, nessa trilogia: familia, trabalho e estudo, vocês já conseguem compreender o quanto de desafios encontrei nesse caminho [...] (SP1)

Isso se aproxima do que pensaBoaventura de Sousa Santos (2020) ao nos apontar que aquarentena tem um caráter desafiante para as mulheres, pois elas precisam, com o título de "cuidadoras do mundo" dialogar com seus diversos papéis dentro e fora da família. Já que precisam exercer suas funções de trabalho, dar conta das tarefas referente ao papel de mãe, dona de casa, estudante, esposa, filhos dentre outros. O autor nos alertapara a necessidade de uma distribuição dos trabalhos domésticos, tendo em vista que com o isolamento todos podem estar em casa e cada um poderá exercer suas funções sem recair apenas sobre as mulheres. O que nos afere um esforço relatado pelo sujeito da investigação,na qual entendemos que essa experiência exige da mulher a utilizaçãode sua criatividade para dar conta dos papéis que lhe são atribuídos.

Desse modo, mesmo com a adversidade,os sujeitos têm buscado reinventar-se em seus processos de entrelaçamento dos papéis referentes a escrita no âmbito acadêmico ou no contexto do próprio trabalho. Quanto aosprocedimentos de escrita, 
nesse período de pandemia,Santos (2020, p.10) mencionaque "[...] $]$ escrevem sobre o mundo, mas não com o mundo. São poucos os intelectuais públicos, e também estes não escapam ao abismo destes dias." Para que essa escrita tenha uma interlocução com a sua essência de sujeito e com esse mundo é preciso mergulhar em si em um processo de descobertas. Nessa perspectiva, encontramos um relato propositivo do SP1, na procura de uma conexão consigo e com o mundo ao seu redor:

A palavra caminhar me ajudou muito, inclusive na escrita. O respeito ao meu tempo, o respeito ao que eu estava vivendo e ao que eu estou vivendo nessa pandemia com 'mil' plataformas. Com duas filhas tendo aula em tempo integral, com casa, marido, trabalho que 'triplicou', os afazeres domésticos todos, escrita e leitura. Então, foram muitos desafios! Eu precisei encontrar uma forma de me recolher. Uma das formas que eu encontrei e deu certo para mim, foi escrever ouvindo músicas com sons da natureza. E isso, tem me ajudado na concentração, tem me ajudado na produção da escrita. (SP1)

Esse “[...] caminhar significa colocar essa posição em jogo, significa exposição, estar fora-de-posição" (MASSCHELEIN, 2008, p. 37). Nesse sentido, a forma de caminhar para fora nos coloca o problema da herança, ou melhor, a ausência dela. É um caminhar que se dá na sujeição da descontinuidade, da fissura ou da quebra(SITJA E REIS, 2009). É um movimento que pode apontar ao sujeito novas descobertas sobre si, sobre o outro emperspectiva de uma escuta interna.

Foi evidenciado outro ponto muito singular dentro das entrevistas narrativas quando SP2 nos disse:

[...] o processo criativo e a criação acadêmica, eu vejo que os professores, os profissionais de educação nesse contexto de isolamento e distanciamento social, eles mantiveram os seus processos de criação. Obviamente, que foi preciso reconfigurar, foi preciso recriar, foi preciso estabelecer novas relações pessoais e novas relações profissionais. Diante disso, nós já podemos acompanhar uma série de revistas com dossiês temáticos que divulgam já uma produção acadêmica a partir desse contexto de pandemia, várias lives. Alguns eventos, todos já em formatos digitais e algumas reuniões de entidades profissionais e sindicais. Então, já há todo um movimento, fruto desse novo contexto da pandemia. (SP2)

Diante dessa problematização, podemos afirmar que o processo criativo do sujeito se elabora no contexto histórico-cultural. O sujeito se desenvolve em uma realidade, de acordo com suas necessidades e valorações culturais interferindo nos próprios valores da vida.Confrontam-se dois polos de uma mesma relação: a criatividade como potencialidade de um ser único e a criação como realização das potencialidades dentro do quadro de uma realidade específica (OSTROWER, 2018) e de uma dada experiência. Como destaca SP2:

[...] a minha experiência com a produção do conhecimento, com o processo criativo nesse contexto de pandemia, ela está configurada em três setores. $O$ 
primeiro setor que é com a pesquisa, onde venho desenvolvendo pesquisa com base de dados do INEP, do Ministério da Educação sobre a qualidade das escolas rurais do Território do Piemonte. Outra pesquisa é fruto diretamente desse contexto de pandemia, nós coletamos através de questionários online informações sobre as condições de trabalho dos professores. Outro setor foi o desenvolvimento de cursos, especialmente, um curso de extensão onde, eu e um outro professor da UNEB, estamos construindo. Iremos ofertar este curso sobre as condições de trabalho na plataforma da UNEAD na UNEB. Então esse movimento nos proporcionou estudo, imersão sobre uma temática que a gente não tinha tanta informação. O terceiro ponto é sobre nossa formação continuada, eu precisei participar de alguns cursos em institutos, em universidades. Cursos que abordassem sobre a Educação à Distância, o ensino remoto, plataforma e softwares para que pudesse tentar proporcionar uma melhor experiência sobre esse processo de ensino - aprendizagem. (SP2)

Os processos criativos apontados por esse sujeito perpassam pela ótica de conquistas do campo profissional e pessoal que tem o ajudado em seu enfrentamento nesse período de pandemia. Nesse sentido, Moraes (1997)sinaliza que os processos criativos possibilitam importantes conquistas no nível interpessoal, intrapessoal e transpessoal. No campo intrapessoal o sujeito pode acessar seu inconsciente em conexão consigo e em um processo de autoconhecimento, confiança, determinação e capacidade de enfrentar problemas diversos. Já no interpessoal possibilita uma capacidade maior de cooperação, adaptação e interação. Por fim, a autora nos aponta que no nível transpessoal essa criatividade pode facilitar uma conexão com o universo, com suas crenças espirituais. O que nos leva a compreender que através desses processos criativos, em que o sujeito é acometido, pode possibilitar novas aberturas e provocar mudanças em sua subjetividade.

No que se refere ao momentoem que a sociedade se encontra,com apresença do vírus que atinge todos os extratos sociais, Santos (2020) nosadverte que a quarentena é discriminatória, trazendo maior dificuldade para uns grupos sociais do que para outros. Desse modo, em seu relato SP2 revela:

[...] compreendo que o isolamento e o distanciamento social num país tão desigual como o Brasil, é atravessado também pela desigualdade do isolamento criativo. Esse é um privilégio para uma parte da população, porque para outra parte não se tem acesso à internet, não tem trabalho formal, perdeu renda, perdeu trabalho e que vive em condições precárias. Esse isolamento social é marcado por um isolamento e abandono. (SP2)

Apesar da importância da reinvenção nesse cenário é válidoacentuarmos que embora o isolamento seja necessário à condição de vulnerabilidade, em que muitos grupos se encontram. Vale ressaltar, que nem todos os grupos conseguem fazer de fato o seu isolamento e que as condições adversas podem ou não possibilitar um processo criativo. 
Um aspecto interessante que emerge a partir do que "é dito" nas narrativas é como os sujeitos são provocadosem seus processos de subjetividade nessa experiência de pandemia. É necessário destacar,que a concepção de experiência aqui compreendida perpassa por aquela que Larrosa (2002) nos provoca a pensá-la e relacioná-la como um acontecimento profundo e significativo.

O período pandêmico é complexoe tem lançado o sujeito a experiências ainda não vividas e é na vivência desses acontecimentosque o sujeito vai se constituindo. Comoaponta Mansano (2009, p. 115) o sujeito

[...], só pode ser analisado a partir de uma processualidade, de um vir a ser que não se estabiliza de maneira definitiva. Ele é construído à medida que experiencia a ação das forças que circulam no fora, e que, por diferentes enfrentamentos, afetam o seu corpo e passam, em parte, a circular também do lado de dentro.

O sujeito que se constrói ao longo da sua caminhada é afetado pelos acontecimentos que dimensionam o seu (re)existir. É nesse sentido que o SP3 diz

Nesse tempo de isolamento social, eu tenho recorrida a poesia, a literatura e me aproximado também da música. Nesses tempos onde a subjetividade nos convoca a sentir intensamente as dores do mundo. Nesse jogo de viver e morrer, de ser livre e de ser privado da liberdade.(SP3)

Em consonância a esse pensar, Santos (2020) nos aponta que arealidade pandémica e as aparições em que se materializanos permite ver o modo como o mundo é interpretado e avaliado, determinando o futuro da civilização em que vivemos. Dessamaneira, os sujeitos são afetados por esse jogo de forças presente no cenário em que se encontram, os levando a uma nova maneira de viver. Como nos lembra Mansano (2020, p. 111):

[...] é nessa dinâmica mutante que os processos de subjetivação vão tomando forma, contando com a participação das instituições, da linguagem, da tecnologia, da ciência, da mídia, do trabalho, do capital, da informação, enfim, de uma lista vasta que tem como principal característica o fato de ser permanentemente reinventada e posta em circulação na vida social.

Os componentes dessa nova realidade ganham uma importância coletiva que passa a impactar, modificar, abandonar, misturar aos elementos da subjetividade de cada sujeito,provocando um movimento. E esse movimento acarreta novos hábitos e novas escolhas. Como sugere SP3:

[...] Tenho escolhido narrativas mais sensiveis para pensar o mundo que rodeio, as pessoas que me cercam e as questões que aparecem na minha produção cientifica e no meu trabalho cotidiano. Por isso, tenho recorrido muito as ideias do Boaventura que nos move a pensar em outra forma de 
fazer ciência. Durante muito tempo a ciência impediu de pesquisas sobre os nossos próprios mundos. O que também nos impediu de transformá-lo. E isso impediu que realidades presentes fossem consideradas como ausentes, ou seja, fossem consideradas inexistentes. [...] (SP3)

Essa narrativa nos aponta a um movimento de mudança através dessa experienciação com uma conscientização de si enquanto sujeito, pois como revelaAmatuzzi (2006, p. 95) " a subjetividade é a consciência de si, a autoconsciência[...] a experiência subjetiva não é a mesma coisa que conhecer, no sentido de um conhecimento objetivo. É muito mais um aproximar-se de sua subjetividade: eis aqui um conhecimento que envolve a pessoa". Isso nos faz perceber que a subjetividade está intrinsecamente relacionadacom aquilo que há de mais profundo na experiência, levando-nos a compreender que a relação sujeito-objetoultrapassa um conhecimento cognitivo dessa subjetividade.

$\mathrm{Na}$ propostado alcance de um conhecimento mais profundo e significativo o relato do SP3 traz questões que ultrapassamo movimento racionalista:

[...] gosto também da ideia de se pensar na ciência que posso recorrer as epistemologias das experiencias e tenho trabalhado nesse sentido, com as narrativas (auto)biográficas para acionar essa forma sensivel de aproximação e experimentação do mundo. Porque estas epistemologias tentam rasurar ou amenizar as linhas tão rígidas da ciência moderna e desses processos que nos colonizaram em tempos de produção cientifica. [...] Gosto do modo como a gente recorre aos outros modos de fazer ciência, criticando essa ciência moderna que nos desumanizou. Que nos colocou nessa condição do não ser.(SP3)

O que percebemos no movimento dessa narrativa é que a pandemia tem provocado ainda mais uma busca de encontros com a subjetividade e distanciando-se do paradigma científico-racionalista. Como bem traz Santos (2020, p. 23):

A pandemia e a quarentena estão a revelar que são possíveis alternativas, que as sociedades se adaptam a novos modos de viver quando tal é necessário e sentido como correspondendo ao bem comum. Esta situação torna-se propícia a que se pense em alternativas ao modo de viver, de produzir, de consumir e de conviver nestes primeiros anos do século XXI.

Essa conjuntura adversa tem provocadoaos sujeitos-pesquisadores arriscar, criar e reinventar,desde queestes permitam-se ser afetados pelos processos de subjetivação que essa mudança social possibilita. Isso nos leva a perceber que não há qualquer tipo de controle no que vai emergir dessa relação entre o sujeito e o mundo em que ele se encontra.

\section{(In) Conclusões}


A pandemia de Covid-19 impactou a sociedade provocando o isolamento dos sujeitos, ocasionando mudanças significativas nas relações, na produção de conhecimento e na percepção de si. Diante do que evidenciamos ao longo do texto, a atividade narrativa se configura como um caminho de resolução de problemas, que nos convoca a lembrar e a refletir as experiências de acontecimentos do cotidiano que são realizadas a partir da trilogia: o eu, o outro e o meio social como referência. Desse modo, falar de si como sujeito-pesquisador exige assumir uma posição específica perante o outro social com quem convive (CAIXETA. et. al, 2017).

Sem dúvida, esse momento de reinvençãoe de desenvolvimento dos processos criativos dos sujeitos - pesquisadores em "tempos de pandemia", nos revelam as diferentes escalas de interpretação. As vidas vãose construindo e se (re)constituindo de forma cada vez mais complexa, abrindo assim, novas perspectivas de repensar a vida em suas dimensões: pessoal e profissional. Ninguém sabe como vai ser o amanhã, mas temos a chance de refletir sobre o hoje para construir um futuro melhor. Questionar a nossa própria prática, por meio de ambientes colaborativos e criativos, na qual se promova um protagonismo perante as pesquisas acadêmicas a partir da experiência vivida.

Nesse cenário,lidar com esse "novo normal" e aprender a viver num mundo onde o futuro se mostra incerto em diversas direções, a tomada de decisão precisa ser feita nesse ambiente deenfrentamento, na qual as informações oferecidas pelas ciências e pela tecnologia são cambiáveis e sujeitas a pontos de vistas contraditórios ( PIETROCOLA y SOUZA, 2019).

Diante da análise das narrativas dos sujeitos-pesquisadores, podemos elencar alguns elementos significativos como: momentos de desafios diante dosdiversos papéis que eles desempenham para poder conciliá-los; busca de interiorização, reflexão e contato com sua subjetividade; ênfase na necessidade formativa para o desenvolvimento profissional, relevância das Tecnologias da Informação e Comunicação (TIC's) que viabilizam as relações sociais e da produção acadêmica e um período que acentua a desigualdade social.

Ademais, os pesquisadores dessa investigação ressaltam a importância dos processos criativos, mesmo com suas limitações, sentindo a necessidade de superar as dificuldades, as quais devem ser comprometidas com a transformação social. Nos fazperceber que as tecnologias, a ciência e a subjetividade se entrelaçam no período de pandemiapara ajudar aos pesquisadores a construção de conhecimentos significativos a 
partir de suas pesquisas, que serão aplicados nos contextos sociais, educativos e formativos.

\section{Referências}

AMATUZZI, Mauro Martins. A subjetividade e sua pesquisa. Revista Eletrônica Memorandum, n. 10, abr/2006. Disponível em http://www.fafich.ufmg.br/ memorandum/a10/amatuzzi03.pdf. Acesso 31 de Ago. De 2020.

Caixeta, J. E., Silva, D. M. S. da, Lima, L. M. de, \& Alves, E. B. S. (2018). Entrevistas narrativas mediadas por instrumentos: investigações sobre a identidade docente. Linhas Críticas, 23(51), 268-289. https://doi.org/10.26512/lc.v23i51.8223

CLANDININ, D. Jean; CONNELLY, Michael. Pesquisa narrativa: experiências e história na pesquisa qualitativa. 2a edição rev. - Uberlândia: EDUFU, 2015.

FREIRE, P. Pedagogia do Oprimido. Rio de Janeiro: Paz e Terra. 1987

JOVCHELOVICH S.;BAUER MW. Entrevista Narrativa. In: Bauer MW, Gaskell G. Pesquisa qualitativa com texto, imagem e som: um manual prático. Petrópolis: Vozes; 2002, p. 90-113.

KRENAK, Ailton. Ideias para adiar o fim do mundo. São Paulo. Companhia das Letras, 2019.

LARROSA BONDÍA, Jorge. Notas sobre a experiência e o saber de experiência. Revista Brasileira de Educação, Rio de Janeiro, n. 19, p. 20-28, jan./abr. 2002.

MANSANO, Sonia Regina Vagas. Sujeito, subjetividade e modos de subjetivação na contemporaneidade. Revista de Psicologia da UNESP, 8(2). 2009. Disponível em file://C:/Users/patti/Downloads/946-Texto\%20do\%20artigo-2985-1-10-20180310.pdf. Acesso em: 30 de Ago. de 2020.

MASSCHELEIN, J. E-ducando o Olhar: a necessidade de uma pedagogia pobre. Educação \& Realidade, Porto Alegre, v. 33, n. 1, p. 35-48, jan./jun. 2008. Disponível em: < http://seer.ufrgs.br/index.php/educacaoerealidade/article/view/6685/3998>. Acesso em: 30 ago. 2020.

MEGALE, Fernando Santaella; TEIXEIRA, Jurema. Notas sobre a subjetividade em Nossos Tempos. Revista Psicologia Ciência e Profissão. Vol. $18^{\text {× }}$ 3. Brasília. 1998. Disponível em: https://www.scielo.br/scielo.php?script=sci arttext\&pid=S141498931998000300008. Acesso em: 29 de Ago. 2020.

MINAYO, M.C. de S. (2010). O desafio do conhecimento: Pesquisa Qualitativa em Saúde. (12 edição). São Paulo: Hucitec-Abrasco.

MORAES, Maria Cândida. O paradigma educacional emergente. $9^{\text {a }}$ Ed. CampinasSP: Papirus, 1997.

MOREIRA, Andrea Godinho; SILVEIRA, Herminia. Teorias da subjetividade: convergências e contradições. Revista ContraPonto, Belo Horizonte, v. 1, n. 1, p. 5869 , jul.201158. 
NÓVOA, António. Histoire\&Comparaison: essaissurl'éducation. Lisboa: Educa 1998.

NÓVOA, A.; FINGER, M. (Org.). O método (auto) biográfico e a formação. Natal, RN: EDUFRN; São Paulo: Paulus, 2010.

OLIVEIRA, Valéria M. de; SATRIANO, Cecília Raquel. Narrativa, subjetivação e enunciação: reflexões teórico - metodológicas emancipatórias. IN: Linhas Críticas, Brasília, DF, v.20, n.42, p.257 - 282, mai/ago 2014.

OSTROWER, Fayga. Criatividade e processos de criação. 30. ed. - Petopólis, Vozes, 2018.

PASSEGGI, Maria da Conceição; SOUZA, Elizeu Clementino. O Movimento (Auto)

Biográfico no Brasil: Esboço de suas Configurações no Campo Educacional.

InvestigaciónCualitativa, 2 (1) p. 6-26, 2017.

PEREZ, C. L. V. Imagens Caleidoscópicas: as narrativas autobiográficas das professoras alfabetizadoras.II Seminário Internacional as Redes de conhecimentos e a tecnologia: imagens e cidadania. Anais... UERJ: Rio de Janeiro, 2003.

PIETROCOLA, M., \& SOUZA, C. R. de. (2019). A sociedade de risco e a noção de cidadania: desafios para a educação científica e tecnológica. Linhas Críticas, 25.

https://doi.org/10.26512/lc.v24i0.19844

RICOEUR, Paul. Percurso do reconhecimento. São Paulo: Edições Loyola, 2006.

SANTOS, Boaventura de Sousa. A Cruel Pedagogia do Vírus. Coimbra- Portugal. Ed. Grupo Almeida. 2020.

SCHÜTZE, F. 1992a. Pressure and guilt: war experiences of a young German soldier and their biographical implications', Parts 1 and 2, International Sociology, 7. p. 187208, 347-67.

SCHÜTZE, F.1992b.Biography analysis on the empirical base of autobiographical narratives: how to analyse autobiographical narrative interviews -part1. Disponível online em: http://www.uni-magdeburg.de/zsm/projekt/biographical/ 1/ B2.1pdf. Acesso em: 17 set. 2020

SERRES, Michel [1985]. Os cinco sentidos. Filosofia dos corpos misturados - I. Trad. Eloá Jacobina. Rio de Janeiro, Bertrand Brasil, 2001

SITJA, Liége Maria Queiroz; REIS, Leonardo Rangel dos. Pedagogias dos des caminhos: educação, humanismos e maneiras de dizer.Revista EntreLinhas, Salvador, EDUFBA, 2009.

SOUZA, E. C. O Conhecimento de si: estágio e narrativa de formação e professores. Rio de Janeiro: DP\&A; Salvador: UNEB, 2006a

SOUZA, Kleyne C.D. de. Narrativas, rua e construção de laços: histórias que se encontram na EJA. In: Revista Brasileira de Pesquisa (Auto)Biográfica, Salvador, V.05, n.14, p.841-858, mai/ago. 2020.

TEDESCO, S. Subjetividade e seu plano de produção. In: QUEIROZ; CRUZ (Org.). Foucault, hoje? Rio de Janeiro: 7 Letras, 2007. 